aggregate capacity of 360,000 horse-power. Only two units of 45,000 horse-power each, have as yet been installed. The system came into operation on November 9 last.

The individual projects, which have been described above, form part of an organized design for the utilization of the resources of the whole of the Tennessee watershed, by means of storage reservoirs in the headwaters, which will retain the run-off during the rainy season and release it during the dry season, so regulating the flow during the whole year to suit the requirements of navigation and to remove the danger of flooding.

Another interesting and important feature of the undertaking is the arrest of soil denudation. Under the influence of heavy rainfall, millions of tons of fertile top soil are removed from the hillsides, and further large quantities are lost by sheet erosion on the plains. This silt would normally be trans ported by the river currents over long distances, but the interposition of a series of dams causes it to settle and enables it to he reclaimed. But, going a step further back in preventive measures, the Authority is engaged in treating the eroded hillsides and encouraging the growth of vegetation with the aid of plant foods, and in particular, phosphates. At Muscle Shoals, a demonstration unit has been built to produce triple superphosphate from the raw phosphate rock found in central Tennessee. The electric power used for this purpose is derived from the hydraulic energy converted at the impounding dams.

The information on which the foregoing article has been based has been courteously supplied by the Tennessee Valley Authority, to which also I am indebted for the photographic illustrations.

\title{
Natural and Artificial Membranes
}

$\mathrm{T}^{\mathrm{H}}$ HE late Sir William Hardy was responsible for the foundation of the Colloid Committee of the Faraday Society, the duties of which were periodically to call meetings at which biologists, physicists and chemists could meet to discuss topics of mutual interest. The fifth meeting of this character was held on April 22-24 at University College, London, under the presidency of Prof. M. W. Travers of Bristol and the chairmanship of Prof. R. A. Peters of Oxford, the subject of discussion being membranes, their properties and functions. This particular meeting was graced by the presence of a number of distinguished foreigners, amongst whom we may include Dr. Ancel Keys of Rochester, Min., L. R. Blinks of Stanford, Mrs. Brooks of Berkeley, Cal., Prof. E. Gorter of Leyden, Prof. R. Collander of Helsingfors, Prof. E. Manegold of Dresden, Prof. Kurt H. Meyer of Genthod-Genève, Dr. W. Teorell of Uppsala and Dr. W. Wilbrandt of Bern, who all took part in the discussion. We were also pleased to note the presence of Profs. H. Mark and W. Ostwald, constant visitors to these meetings. It was to be regretted that several distinguished scientific workers were unable to present their papers; these included Profs. A. Krogh, Newton Harvey, E. Ponder, W. J. V. Osterhout and Cole.

It was clear from the contributions and from the discussion that in spite of the importance, both structural and functional, of membranes in organized living systems, we are still a long way from obtaining a complete description of the microstructure of even one of these or a general interpretation of their behaviour. It would appear that all natural membranes are composite in the sense that they contain both a lipoid-like and a non-lipoid component. The structural relationship of the components to each other is still sub judice. Exponents were not lacking of the extreme view of complete stratification of each component, one possibly in a monolayer, as well as those who upheld the view of a systematic mosaic or even haphazard intermingling. Some species of interaction, at least between the components of each 'phase', appears necessary to account for the physical properties of the complete membranes.

Whilst cationic and anionic permeability of the protein component of the membrane and the 'solubility of organic substances' in the lipoid component, as well as the ionic partition as defined by the Gibbs - Donnan membrane equilibrium are readily understandable in general terms, it appeared to many that these now well-recognized and important factors do not suffice to account for all the observed phenomena. So many questions were asked by our biologist friends at the meeting for the consideration of the physicist and chemist that it seemed difficult at times to realize how much progress had been made since the first meeting summoned by the Colloid Committee. There were three questions raised of unusual interest to many non-specialists present, to which no generally satisfactory answers could be given. These were the apparently abnormal behaviour of the potassium ion, the origin of bio-electric phenomena and the mechanism of narcosis. 
In a medium containing a variety of salts, no satisfactory mechanism has been proposed for the relative enrichment in potassium of a portion separated from the bulk by means of a membrane, for example, red cells as discussed by Dr. M. Maizels. It was doubtful whether membrane charge, ionic size, solubility or complex formation could be the operative factors. It may be significant that not only is the lipoid/water partition coefficient for many potassium salts or complexes favourable for such separation, a view supported by Prof. Osterhout, but also that the ionic mobility of the potassium ion is some fifty per cent greater than that of the sodium ion, and thus in a dynamic system with migrating water as medium some separation should be possible.

According to Profs. S. C. Brooks and W. Stiles, separations due to mobility difference might be effected by exchange with ions, for example, those of carbonic acid produced in the metabolism. But if the final dynamic distribution of ions be calculated on the basis of a steady Donnan diffusion equilibrium, Dr. Teorell showed that under biological conditions the accumulation due to interdiffusion could not amount to more than 2 per cent.

If separation be accomplished by continued ionic transport involving an electric potential or a counter current of flowing liquid, it serves to emphasize the fact frequently forgotten by the non-biologist that these interesting properties are exhibited by living systems, and as such their dynamic state, involving possibly a continuous and steady flux of ions or liquid, may prove of paramount importance.

Such a theory demands the existence and the maintenance of an osmotic or an electrical gradient present within the membranes. From the discussion supported by Dr. G. S. Hartley, it was considered that diffusion or non-polarizable potentials could perform work ; Prof. H. Freundlich suggested that work could also be obtained from temperature gradients (Soret effect). Drs. D. Gatty and P. B. Dean pointed out that redox potentials cannot be responsible for ionic accumulation. Dr. F. C. Steward and Dr. Ancel Keys inclined to the view that water and salt transport through plant cells and gills were due to metabolic processes oxidative in character.

Similar considerations may apply to the phenomena of bioelectric potentials. Some confusion exists owing to the misapprehension of the facts concerning the Donnan potential; namely, that the membrane potential can only be measured either electrostatically by the use of non-reversible electrodes in the two solutions separated by the membrane, or by the difference in the potentials given by each solution separately to a reversible electrode against a standard electrode in a solution containing the common ion. In spite of the fact demonstrated beautifully by Prof. Kurt Meyer that both acidophil and basophil membranes can be detected by staining methods in systems exhibiting bioelectric phenomena, it is not only doubtful whether these methods are certain criteria for selective ionic permeability, but also the serious difficulty that currents can be drawn from these presumably readily polarized systems does not appear to be surmountable unless a dynamic mechanism is operative.

A number of papers, including those of Profs. K. C. Cole, L. R. Blinks and Drs. Dean and Gatty, involved the use of electrical measurements to obtain information as to the equivalent electrical circuit which a cell with various hypothetical structures would present; inter alia it was brought out that Frickes' previous estimate for the thickness of the red cell wall must be considered in error.

An excellent summary of the views as to the origin of potential differences obtained in nerves was given by Dr. S. L. Cowan, who showed that diffusion potentials alone are not adequate. Dr. H. Rosenberg elaborated the core conductor system, whilst Mr. J. Z. Young discussed the chemical evidence as to the structure of the axon and the myelin sheaths of the nerve. He suggested in a general way that radially orientated lipoid layers may be responsible for nervous stimulation. It may be significant in this connexion that the phase boundary potentials exhibited by monolayers at interfaces are generally much larger than those potential differences obtainable by a Gibbs Donnan distribution in biological systems containing a relatively high salt concentration; such monolayers on polarization naturally accumulate ions, and provided there exists some mechanism for destroying or changing the monolayer on stimulation, the result would be an ionic flow. Papers were communicated on the properties of protein monolayers by Prof. E. Gorter, by Dr. J. S. Mitchell and Dr. J. H. Schulman. The Overton lipoid solubility hypothesis of narcotic action was revived in new form by Prof. Kurt Meyer, utilizing oleic acid as the model for the lipoid in evaluating the critical partition coefficients.

Prof. A. J. Clark, in a critical review, pointed out that the problem did not appear as simple as suggested by either Overton or by Traube, and that it appeared probable that selectively narcotizable and differentiated areas were involved. Several anæsthetics do not appear to conform to the oleic acid solubility rule, and the response of various types of nerve systems is not identical. The hypothesis advanced by Dr. Schulman and the present writer, in which interaction of the polar head or the non-polar portion 
of a narcotic with a lipo protein complex, appears to overcome the disadvantage of the older theories, but in its present state of development is too general and vague to be of much practical utility.

Papers dealing with the more practical side of artificial membranes were presented by Prof.
Manegold and Dr. W. J. Elford. Dr. G. S. Adair gave a paper dealing with refinements of the Donnan membrane equilibrium.

The meeting was one full of interesting topics, but somewhat discursive owing to the attempt to deal with too many diverse phenomena at one time. Eric K. Rideal.

\section{The Soviet Expedition to the North Pole}

$\mathrm{T}$ HE institution of a station for scientific research within a few miles of the North Pole marks a new phase in polar exploration, and is a development of the intensive exploration which the Soviet Union has pursued in Arctic regions during the last few years. The earliest attempts to penetrate high northern latitudes, away back in the sixteenth and early seventeenth centuries, were inspired by the hope of direct trade routes with the Far East and were alternatives to the still older attempts to find the NorthWest and North-East Passages. The early nineteenth century saw a revival of the northern ventures, and the Franklin disaster in the middle of that century led to a focusing of interest in polar regions, and stimulated journeys that were more adventurous than scientific in their outlook. But in an age of exploration that relied on man-hauled sledges and preserved food, that feared low temperatures and had to reckon with inevitable scurvy, the inner polar regions maintained their isolation.

Petermann's hypothesis of an open polar sea led to more than one failure and was utterly refuted by Nares, Greely and others. Then Nansen, imbued with scientific aims, brought a new technique to bear on the problem. The pack-ice that had thwarted his predecessors was to afford him the means of advance, and so in the drifting Fram he penetrated to lat. $86^{\circ} \mathrm{N}$., and on foot some miles farther north. Nansen discovered a deep, landless polar ocean covered with drifting pack-ice. There the solution of the polar problem was to rest for some years. Even if Cagni beat Nansen's record by a few miles and Peary actually reached the Pole in 1909, these expeditions were mainly adventurous achievements and added little to scientific research. Amundsen's attempt to emulate Nansen had its value but failed to gain a high latitude.

Sledge and ship had both played their part in different ages : air-voyaging was next to be tried. Early attempts were naturally failures. In 1925 Amundsen reached $87^{\circ} 43^{\prime} \mathrm{N}$. by air and returned with difficulty. In 1926, with Nobile, he crossed the Pole by airship, and in the same year Byrd also reached the Pole. These attempts showed not only the possibility of flying in arctic regions but also revealed large smooth floes with a relative lack of pressure ridges in the vicinity of the Pole. None of these expeditions, however, stayed more than a few hours, and others much less, at the Pole or anywhere in inner polar regions. Thus observations were casual and of little help, while little or no oceanographical work could be done.

Prof. O.J. Schmidt, who is in charge of the Soviet expedition to the Pole, aims at a more valuable type of exploration in placing a party in the vicinity of the North Pole for at least twelve months. The experience of arctic flying and arctic conditions generally that Soviet aviators and explorers have gained in recent years makes this possible. In connexion with the northern sea route between Europe and the Siberian rivers, of which much use is now being made, meteorological observations from the far north will be invaluable, especially in relation to the movements of the pack-ice. These observations are to be taken both at sea-level and at high altitudes. The direction of the ice drift will be studied and Prof. Schmidt points out that the station will be shifting continually in position, but it is not known if this shift will be steadily in one direction or rotatory around a certain point. In any event, these movements will facilitate soundings of the depths of the Arctic Ocean, of which little is known.

Chemical and physical analyses of the water are important in relation to the inflow of Atlantic water, and the bearing of that inflow on ice formation and ice-wastage. Good and bad ice years have long been recognized at Spitsbergen, Greenland and in the Kara Sea, but the factors involved are not understood and prediction is impossible. Magnetic and geophysical researches are also planned and biological examinations of the seawater will be made. The station will be in radio communication with Moscow, and, it is hoped, in flying communication through many months of the year. The smooth floes afford a suitable 